\title{
Analysis and Countermeasure Research on the Death Rate of the Vulnerable Road Users in Traffic Accidents
}

\author{
Ying MEI \\ Wuchang district people's procuratorate, Lujia Street 299\#,Wuhan,Hubei,China
}

619947782@qq.com

Keywords: Traffic accidents, Vulnerable Road Users, Mortality.

\begin{abstract}
Traffic accidents have become the world's highest mortality factor between the 15 and 29 years of age. Based on the analysis of traffic accidents data of 2 years, which found that the death rate of the vulnerable road users was the highest, but in most cases it was the cause of traffic accidents. Based on the data statistics, this paper analyzed the main causes of the traffic accident mortality, the main sections, the main time periods and the main behavior factors of the vulnerable road users. And in view of the above analysis results, putting forward the measures to reduce the traffic accident mortality of the vulnerable road users based on the law and policy.
\end{abstract}

\section{Introduction}

I worked in the people's procuratorate at the district level during 2015 and was responsible for the processing work of traffic accident case for half a year. During the period, I handled a total of 127 cases of traffic accidents, which involved the death toll of 33 people, injured 163 people. This directly caused the problems such as the social burden, serious economic losses, the family main source of income concerned, the medical expenses exponentially increased, the burden of human expenses increased and so on. Statistics found that more than $70 \%$ of the deaths are pedestrians, electric bicycle drivers, motorcycle drivers and passengers. In these vulnerable road users, more than $70 \%$ of the people's behavior is a direct cause of the accident, which brings difficulties to the handling of traffic cases. It is also found that the number of deaths and injuries in traffic accidents is much higher than the number of victims of violent crime cases at the same time, and the economic losses involved are also much higher than the violent crime. After consulting the relevant data, found that traffic accidents have become the world's highest mortality factor between the 15 and 29 years of age[1] (Figure 1). For middle-income countries, road traffic deaths and injuries caused economic losses accounting for $5 \%$ of GDP, and this ratio is very considerable and in recent years there is an upward trend (Figure 2), which allows us to have to attach importance to the losses caused by traffic accident. As can be seen from the figure 2 also, compared with $4 \%$ a year in the population growth rate and a $16 \%$ increase in the number of motor vehicles, traffic accident death rate of growth is slow over the years, which indicates that legislation, formulate regulations and other measures had achieved a big success in recent years. It also can be seen the regulations and policy impacts on the traffic accident mortality from the differences of several countries in drunken driving standards in Table 1. Therefore, this article will be based on the analysis of the death data of China's vulnerable road traffic accidents, and offer a proposal to reduce the traffic accident mortality from the legislation and the policy point of view. 


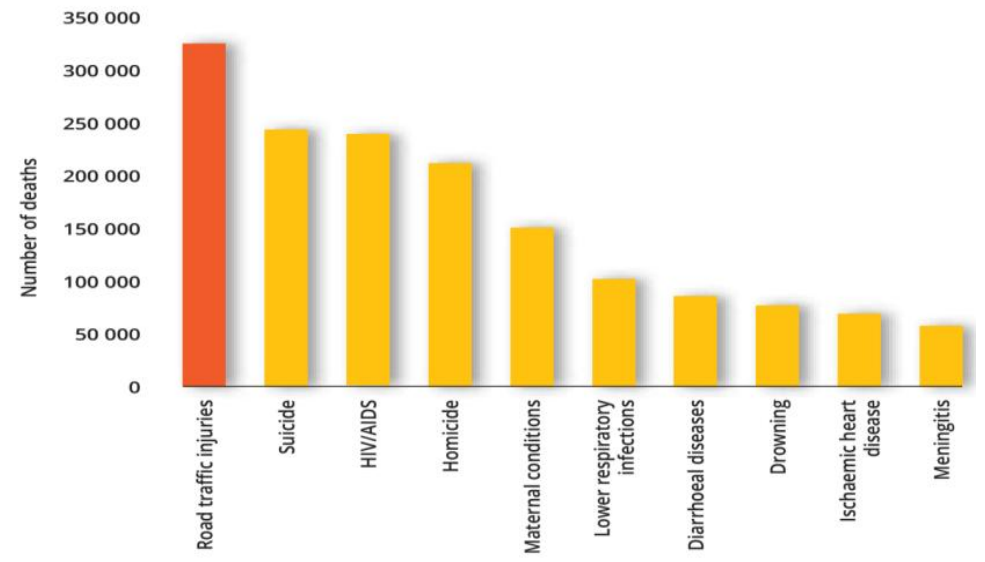

Fig.1 Top ten causes of death among people aged 15 - 29 years, 2012

(Source: Global Status Report on Road safety 2015)

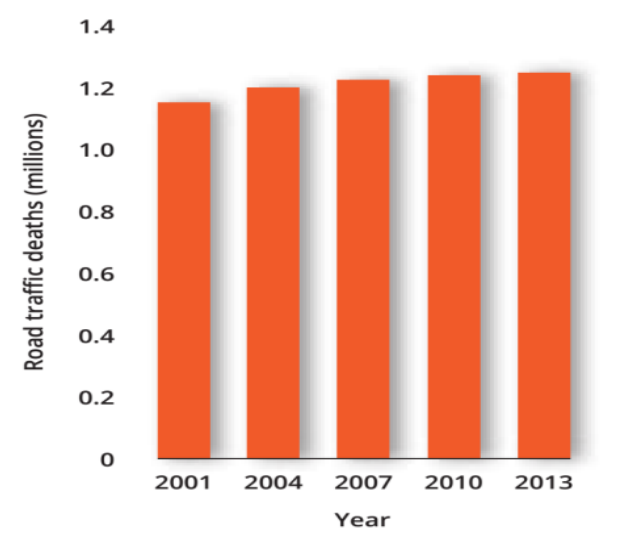

Fig. 2 Number of road traffic deaths, worldwide, 2013

(Source: Global Status Report on Road safety 2015)

Table 1 Percentage of Casualties of Drunk Driving in Difference Countries (Data from WHO)

\begin{tabular}{|c|c|c|c|c|c|}
\hline Nation & $\begin{array}{c}\text { United } \\
\text { States }\end{array}$ & $\begin{array}{c}\text { United } \\
\text { Kingdom }\end{array}$ & Germany & Japan & China \\
\hline BAC limit[g/dl] & 0.08 & 0.08 & 0.05 & 0.03 & 0.02 \\
\hline $\begin{array}{c}\text { road traffic deaths } \\
\text { involving alcohol[\%] }\end{array}$ & 31 & 16 & 9 & 6 & 4 \\
\hline
\end{tabular}

\section{The Analysis of Vulnerable Road Users' Mortality}

I compiled the procuratorate to accept traffic accident cases in 2014 and 2015, the total number is 624 , the number of dead is 171 , the number of injured people is 813 . The victim of road use type proportional distribution is shown in figure 3. It can be seen that, pedestrians, motorcycle and bike riders accounted for $70 \%$ of deaths in the traffic accident, in 2013, the released data (figure 5) of the national ministry of public security attest the proportion was as high as $61 \%$, this suggests that pedestrians, motorcycle and bike riders of these vulnerable road users are the main part in the traffic accident victim. 

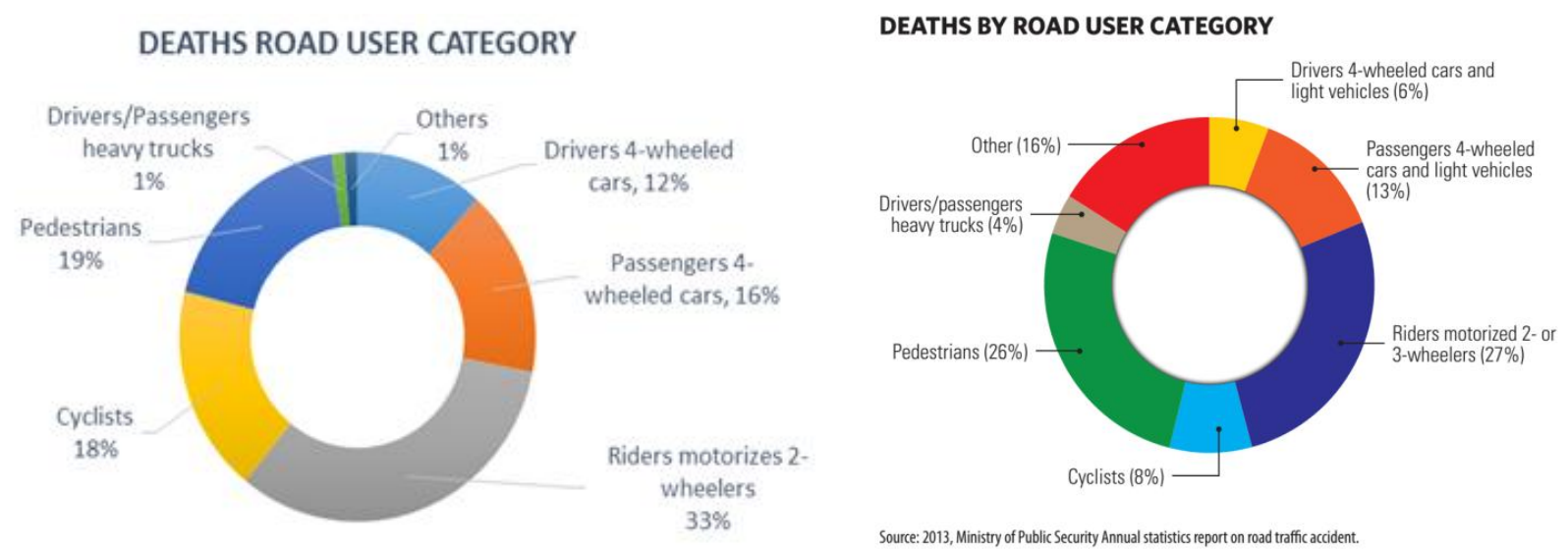

Fig.3 Deaths Road User Category, 2014

Fig.4 Deaths Road User Category,2013,Nation and 2015 , Wuchang Administrative District

\section{Analysis on the Proportion of Injured Area in the Vulnerable Road Users.}

With the rapid increase of urban car ownership, parking is becoming a real problem. Due to the car parking and occupy the non motorized vehicles are very common. Therefore, in urban road, non motor vehicle road does not have enough driving and had to borrow motorized vehicles. Thus leading to the road into a motor vehicle and non motor vehicle mixed road conditions.

And the road outside the city is a pedestrian, non motor vehicles and motor vehicles completely mixed road. The situation of this mixed Lane leads to the frequent occurrence of traffic accidents between the vehicle and the vulnerable road users.

Due to the lack of protection of vulnerable road users, often become victims of traffic accidents. For example, when a pedestrian and vehicle collision, people's heads tend to be higher than the speed of the vehicle hit the car, resulting in serious injuries to the head and even death, as shown in figure 5.

The bicycle and motorcycle driver injured site after impact with the similar situation. According to figure 3 in vulnerable road users death reasons ratio statistics (Figure 6) can be seen, head impact injury reaches the highest proportion of $42 \%$, has become the main reason for motor vehicles and vulnerable road users to death.

Therefore, protecting the head is effective measures to reduce the traffic accident mortality, however, China does not have for pedestrians and non motor vehicle occupant provisions must wear a helmet of the legal provisions. For example, although the law provides for motorcycle occupants must wear a helmet, but in the actual situation, due to the lack of regulation, especially in non urban areas, the provisions of the law never fully implemented.

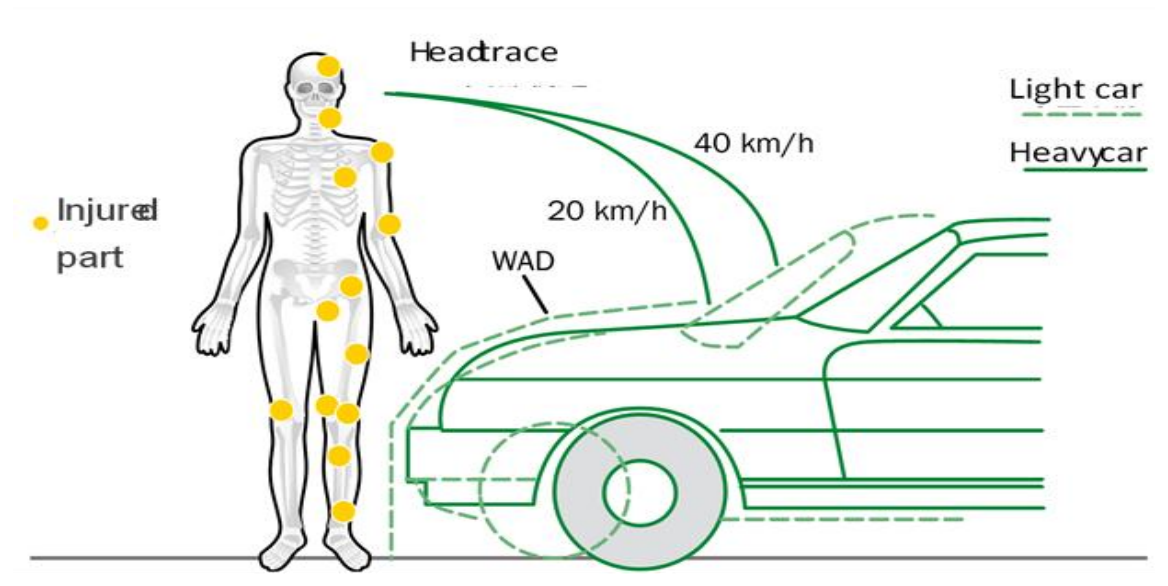

Fig.5 Injured area when pedestrian is hit by a vehicle 


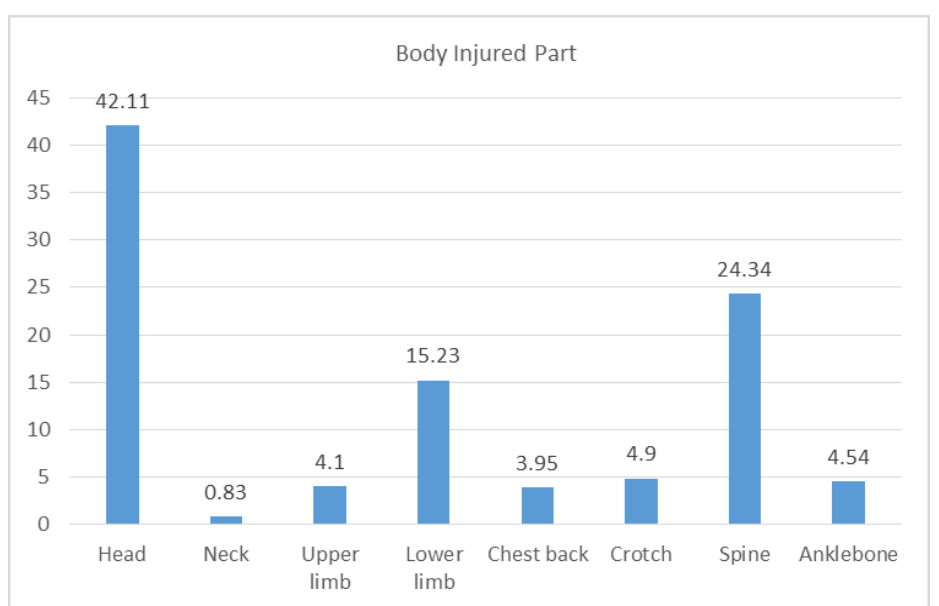

Fig.6 Injury ratio of body parts in traffic accident

\section{Traffic Accident Mortality Road Section Analysis.}

Figure 7 shows the distribution of the sections of the vulnerable road users. The highest reaches $49 \%$ in the county road, the traffic accident mortality rate, followed by the city road. The main reason of county road traffic accident death rate is high speed, and the lack of legal and regulatory measures of traffic on the road.

With the development of China economy, county road quality has been improved. In the county and township roads, vehicle density is relatively low, and no traffic lights, camera, and vehicle speed measurement equipment, also due to the legal speed limit provisions of fuzzy, motor vehicle usually in these sections with higher speed.

Owing to these sections not set fences, road at any time of pedestrian, bicycle or motorcycle across the road, so the occurrence of high probability of traffic accidents, and in the event of traffic accidents, the mortality is relatively high. State Road and provincial road speed limit is generally $70 \mathrm{~km} / \mathrm{h}$, but there are a lot of isolation barrier openings.

Because of the many openings there are no traffic lights, at the same time pedestrians, cyclists and motorcyclists who safety awareness is not strong, so random walking is a common phenomenon, which resulted in leading to the possibility of traffic accident is relatively large.

But relevant data shows that in the national or provincial road, setting a rate limiting facilities and traffic control facilities, traffic accident mortality was significantly lower than the mortality of traffic accident occurred in the county and township road.

Roads in urban areas generally have speed limit signs on the road, there is no speed limit signs on ordinary roads. Urban road traffic accident deaths are mostly in the urban fringe, the reason is that the road is wide, the vehicle density is small, the motor vehicle speed is relatively fast. According to statistics, adult pedestrians if the speed is less than $50 \mathrm{Km} / \mathrm{h}$ of the car crash, the probability of death in the following $20 \%$. However, if the speed of the car crash $80 \mathrm{Km} / \mathrm{h}$, the risk of death is almost $60 \%$. Therefore, the root cause of the increase in traffic accident mortality rate is not the speed limit of the motor vehicle.

In addition, pedestrians, cyclists and motorists on the urban road red light running, retrograde illegal phenomenon is very common, and once when they and motor vehicle traffic accidents, these vulnerable road users may be more susceptible to death. 


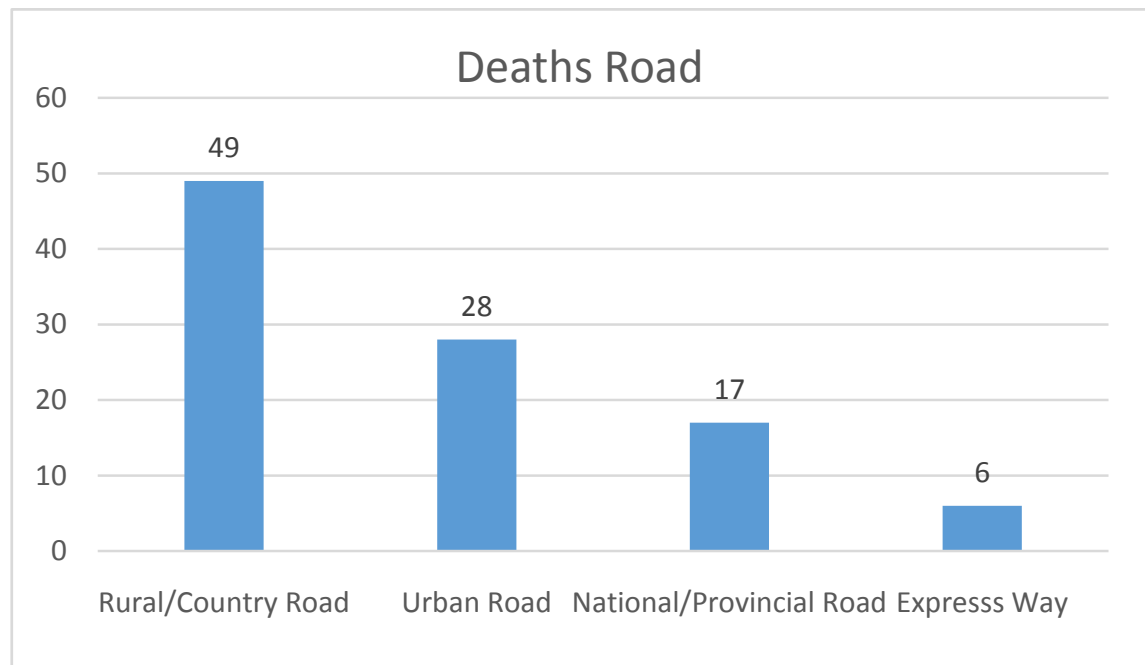

Fig.7 Distribution proportion of traffic accident mortality of vulnerable road users

\section{Time Analysis of Traffic Accident Mortality.}

Figure 8 shows the distribution of vulnerable road users in the time of the occurrence of traffic accidents, it can be seen that the maximum time of death rate is after dinner. In the evening, because of the low road visibility and fewer vehicles, vehicle speed is often faster, it is easy to occur accident when encountered unexpected situations, leading to accident deaths.

In 2013, the Chinese added drunk driving into the criminal law. It significantly reduced the motor vehicle driver's drunk driving accident. But there is no legal provisions for non-motorized vehicle driver's drunk driving. Traffic accidents after dinner $45 \%$ of deaths are related to alcohol. And non-motor vehicles drunk driving after dinner is one of the main reasons for traffic accident, death rate of which is higher. After dinner, there are $45 \%$ traffic deaths related to drinking, non-motorized vehicle driver's drunk driving is one of the important reasons for the high mortality rate after dinner.

In addition, in the rush hour 16:00-18:00 and 06:00-08:00, the road is crowded; so pedestrians and cyclists in order to catch the time often resort to illegal behavior, which leads to traffic accidents and the mortality rate is relatively higher.

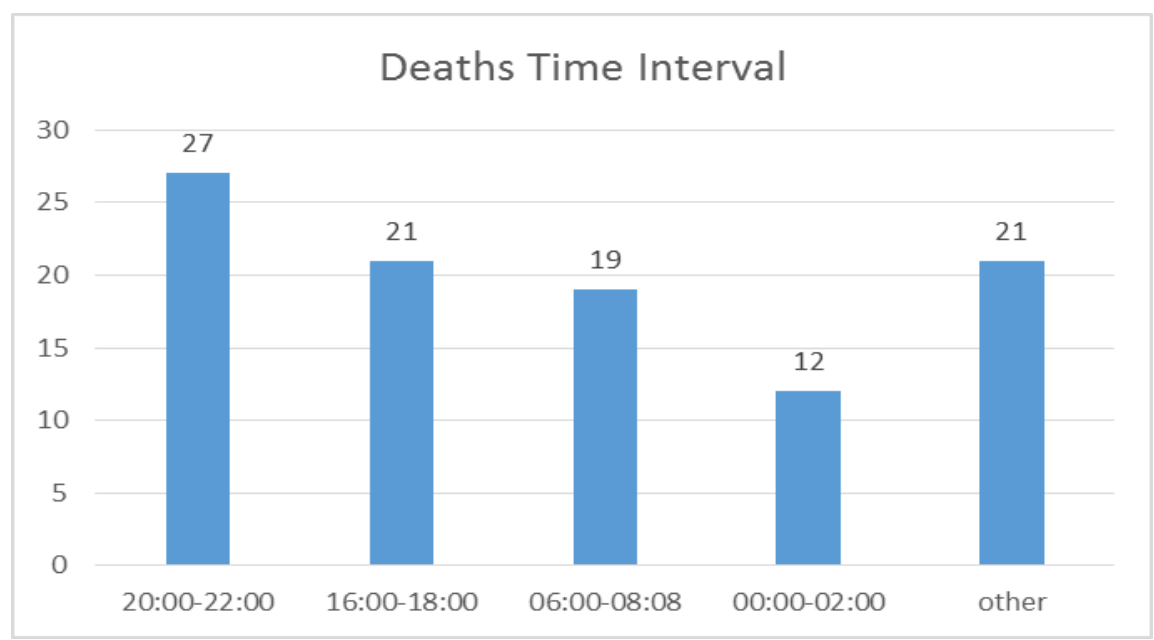

Fig.8 Time proportion of traffic accident mortality of vulnerable road users

\section{Traffic Accident Mortality Behavior Analysis.}

In the vulnerable road users, there is widespread phenomenon such as the using of the road non-compliance with the traffic signal, retrograding, taking up the road, speeding and other acts. Based on data and statistics results of the past two years in this area, more than $70 \%$ of the deaths 
were caused by human behavior, that is, they are victims, and the accident initiators. The reasons have two aspects.

The One hand is legal and policy reasons. China's current regulations on traffic safety control are aiming to protect vulnerable groups, that is, as long as the traffic accident occurs, the main responsible party must be the driver of a motor vehicle, the legal provisions, which seems to protect the weak, in fact, is detrimental to the disadvantaged groups, contributed to the vulnerable road users, and make them underestimated the risks and costs of violate the rules and regulations. The law in China even breeds the "PengCi" phenomenon, which is some pedestrians and cyclists intentionally ramming motor vehicle for a living, and using the legal provisions to blackmail the motor vehicle drivers.

On the other hand, the lack of education and traffic safety laws and regulations. China's traffic safety laws and regulations are mainly for motor vehicle drivers, drivers must study and pass the examination of relevant laws and regulations. And for vulnerable road users, there is no agency and time to let them learn related content. Their awareness of traffic laws is not strong, traffic safety awareness is extremely indifferent, even lacking of the awareness of the cost of traffic accidents, which is the fundamental reason for their risk of illegal behavior .

\section{Measures to Reduce the Traffic Accident Mortality of Vulnerable Road Users}

\section{Need Road Safety Regulations for Vulnerable Road Users.}

The vulnerable road users on the one hand is the traffic accident victims, at the same time, in many cases, is a direct cause of the accident. Due to the lack of protective measures, the accident death and severe injury rate is very high, and usually they are low-income groups and families, the traffic accident consequences will get their families in trouble and also bring the burden to the society.

The core of reduction the traffic accidents and mortality in vulnerable road users is to develop traffic safety regulations especially for them, regulate their road use behavior, as well as the establishment of a fair and impartial legal provisions on the basis of accident liability. For example, do not occupy non motorized road, riders must wear safety helmet, violation scope and the penalty of pedestrians or cyclists, non motor vehicle drivers drunk driving processing, annual evaluation system for electric bicycle and pedestrian overpass or tunnel sections and requirements to set up, all kinds of road lighting requirements, and highway or country road intersection must install traffic lights and so on.

\section{Need to Develop Relevant Policies to Support the Road and New Technologies to Monitor Vehicles.}

Current regulations of vehicles traveling on the road mainly rely on the intersection and the road surface scattered set of cameras and artificial site management. This way can only monitor the legal license plate of the car, instead of motorcycles, electric bicycles, which resulted in the blank monitoring and management of motorcycle and electric bicycles. Due to the lack of management, the road safety law and traffic rules on motorcycles, electric car is not binding, the number of two models of large and illegal driving phenomenon is very prominent, which leads to the probability of a large number of traffic accidents.

Through the camera to monitor the road conditions can only be carried out on the intersection and small sections of the vehicle monitoring, which cannot work in the whole process, continuous monitoring of the vehicle. Do not have the ability to monitor the vehicles driving on the road, highway, national highway, provincial highway and rural road. Therefore, there are many violations in the road, and the accident rate and mortality rate is higher. The government should formulate relevant policies to support the "whole journey, all models, all-weather" vehicle monitoring technology, such as the use of GPS technology, with the accurate location algorithm, networking and Internet technology, realize the whole trajectory on all types of vehicles, speed, and direction monitor, 
and verify it combined with the data collected by the intersection camera, which totally solve the problem of vehicle monitoring technology, and support the implementation of traffic regulations.

\section{Road Separation and Speed Limit on Urban Road.}

The government should increase the investment in road construction, and separate the sidewalks, non motor vehicles and motor vehicle lanes, especially in the rural highway, it is necessary to isolate the motor vehicle and bicycle lanes and avoid traffic accidents among the high-speed motor vehicles pedestrians, and bicycles. Also it should be clear that the city road speed limit, set up the speed limit sign, in addition to the elevated road, the other urban roads will be the speed limit of $50 \mathrm{~km} / \mathrm{h}$, reduce the traffic accident mortality in the night, morning and evening traffic peak.

\section{Establish the Legal Education Mechanism for Vulnerable Road Users.}

Establishing road safety laws, regulations and institutions for vulnerable road users. Combined with the non motor vehicle annual inspection, illegal punishment, strengthen the education and evaluation of vulnerable road users, enhance their awareness of road safety regulations. Besides, put the traffic safety regulations and knowledge content into the primary and secondary school textbooks. Moreover, set up the corresponding traffic safety and traffic accident disposal training courses, so that students will be enhanced the awareness of traffic safety and avoid traffic safety hazards.

\section{Summary}

In this paper, the existing traffic accident data were analyzed. In view of the reasons, section, time interval and the behavior of the high mortality, the statistics and analysis were carried out. In view of the problem of the high mortality rate of the vulnerable groups of roads, it is necessary to formulate the relevant laws and regulations of traffic safety, which can alleviate the problem radically. At the same time, we must support some new technologies to solve all kinds of vehicles in a variety of ways to monitor the whole problem, and to protect the implementation of laws and regulations; This paper argues that the pedestrians and non motor vehicle road should be separated, urban road should limit speed and reduce motor vehicles and vulnerable road users traffic accident mortality; it also propose the establishment of legal education system for vulnerable road users, and enhance the awareness of traffic safety.

\section{References}

[1] Global status report on road safety 2015,WHO,2015, pp.2-5

[2] G.R. Mettam, L.B. Adams, How to prepare an electronic version of your article, in: B.S. Jones, R.Z. Smith (Eds.), Introduction to the Electronic Age, E-Publishing Inc., New York, 1999, pp. 281-304.

[4] R.J. Ong, J.T. Dawley and P.G. Clem: submitted to Journal of Materials Research (2003)

[5] P.G. Clem, M. Rodriguez, J.A. Voigt and C.S. Ashley, U.S. Patent 6,231,666. (2001)

[6] Information on http://www.weld.labs.gov.cn 